sold in other large cities, but the local meat inspection system has made it unprofitable for shippers to consign inferior meats to this city and hence the quality of shipments has improved, both in dressed meats and live stock intended for slaughter.

\title{
DETROIT, MICH.
}

\section{By Delos F. Wilcox, Pr.D., Secretary Detroit Municipal League.}

Detroit gets its meat supply from various sources. Mist of the dressed meat is received from the Chicago packing houses in car lots. Probably more than half of the total supply of meat, however, is received from various parts of Michigan, and slaughtered here. The animals are generally brought in by rail, although some are hauled to the city by farmers from the surrounding country. The meat brought in by individual farmers is not always seen by the inspectors. A very large part of the animals brought here for slaughter pass through the Detroit stockyards. There are, however, a large number of private slaughter-houses in the city, more than forty wholesale meat dealers and upwards of 500 retail markets. When the conditions at the Chicago stockyards were being investigated a few months ago, there was some special investigation and criticism of local conditions which led to the passage of more stringent ordinances regulating the equipment of the stock-yards and the inspection of meat.

Detroit has for the last twenty years had two meat inspectors. They were originally appointed by the Common Council, but are now appointees of the local Board of Health, whose members have since 1895 been appointed by the Governor of the State.

Three years ago the Legislature passed a general act authorizing the appointment of one or more meat inspectors by any city or village in this State, and conferring upon the local authorities power to license the meat business and regulate slaughter-houses by ordinance. Authority is given to exclude from the city or village the meats from any outside slaughtering-house which does not conform to the rules laid down. Furthermore, the municipality is authorized to establish a public abattoir, if it so desires. Meat that has already been inspected by Federal authority is exempted from local inspection except as to the place where it is sold and as to changes, decomposition, etc. This law contains stringent provisions for the regulation of slaughter-houses, which must be contained in any local ordinance adopted under the terms of the act. Under special laws, however, Detroit had long since been equipped with a meat inspection system and ordinances controlling it.

The following rules have been adopted by the Detroit Board of Health, governing the use and care of slaughter-houses within the limits of the city, and every owner, lessee or occupant of a slaughter-house is notified and required to obey them;

"First. All slaughter-houses, pens or enclosures connected therewith, shall be kept in a proper sanitary condition. 
"Second. Slaughter-houses shall have water-tight floors, which shall be thoroughly washed off after slaughtering is completed.

"Third. Slaughter-houses and pens shall be whitewashed inside at least once a month.

"Fourth. All slaughtering of animals shall be conducted without exposure to the public.

"Fifth. All offal shall be removed on the day of slaughtering.

"Sixth. Iron gratings (bars not over one inch apart) are required to head all outlets to sewer from floor of slaughter-house.

"Seventh. All animals kept in yards attached to slaughter-houses must be treated in a humane manner, and, if kept there over twelve hours, must be fed and watered. Bleating calves shall not be kept in pens over twelve hours.

"Eighth. The meat inspectors of the Board of Health shall have free access to premises at all times in the performance of their duties.

"Ninth. It shall be unlawful to slaughter any animals in sheds or barns. A slaughter-house designed and built in accordance with the law is the ONLY place where such killing may be done, and no nuisance shall be committed."

The Detroit Board of Health act itself provides that "Neither blood, bristles, hair, entrails, or any offal whatever shall be allowed to enter any public sewer, and all entrails shall be emptied, all blood cooked, and all offal cleaned up at the place of slaughtering within six hours after such slaughtering takes place."

Until recently the city ordinance governing the stockyards has provided that they be paved with cobblestone, and of course under these conditions the floors could not be properly cleaned. The new ordinance requires that "All stockyards in the City of Detroit shall be thoroughly drained, and paved with vitrified brick or other suitable material, which may be readily and thoroughly cleaned of all accumulations, such drainage to be connected with a public sewer, and the pavement laid in such a manner as to keep the same dry and free from standing or stagnant water."

The new ordinance prescribing methods of meat inspection provides that "It shall be the duty of said inspectors personally to view as far as possible all meats and poultry offered or kept for sale for human food in said city; to visit all stock yards, barns, commission houses, slaughter houses, and all other places in said city, and to inspect all animals delivered, received, confined or held in them for slaughter, and the carcasses of all animals already slaughtered for human food, and to visit all places, including all steam and electric railway stations, depots or freight houses, steamboat wharves or freight houses belonging thereto, express houses, cars or wagons where meat for human food is delivered to, received, stored or held by railway corporations, steamboat owners, or other corporations, firms or persons, kept or offered for sale, and to inspect and ascertain the condition of said meat.

"Each of said inspectors shall have authority, and it shall be his duty to condemn, take immediate possession of, confiscate and destroy any meat or poultry, sold or offered for sale, in violation of this or any other ordinance of the city, and make complaint before the proper officer for every violation of said ordinance, coming to his knowledge, and it shall be unlawful, and a 
violation of this ordinance for the owner or any other person to remove, secrete, sell or offer for sale any live animal or animals, fish, game or poultry, or the carcass or carcasses of any and all slaughtered animals, fish, game or poultry, oysters, clams, lobsters, or other sea food, after the same shall have been taken possession of, confiscated and condemned by either or both of said meat inspectors.

"Said inspectors shall at all times have the right to open any and all barrels, boxes or packages in their discretion at any of said stations, depots, wharves, freight houses, warehouses, commission houses, express houses, cars or wagons, or other places in which they have good reason to believe, any carcass of any animal, fish, poultry or game, oysters, clams, lobsters, or other sea food, or other article of meat shipped, offered or intended to be offered for sale for human food, is contained or concealed, and take immediate possession of, confiscate, condemn and destroy, if necessary."

The meat inspectors shall have the right, and it shall be their duty to condemn and cause to be slaughtered immediately and destroyed, so that the same shall not be used for human food all calves under four weeks old, or which are diseased, emaciated or otherwise unfit for human food; and all badly crippled, overheated or diseased hogs, cattle, sheep or lambs, which for any other reason are unfit for human food.

It would seem as if two inspectors would have their hands more than full in carrying out the provisions of this ordinance for a city of 350,000 inhabitants. It is claimed, however, that they visit the principal wholesale markets every day and get around to the retail markets once or twice a week. Complaints requiring their special attention are occasionally received. The city inspectors do not look after shipments of dressed meat, but see it only when and where it appears for sale. The animals brought into the city for slaughter are, however, subject to inspection. The inspectors have summary authority to condemn unsound meat or diseased animals intended for slaughter. The usual method of handling condemned meat is to treat it with kerosene oil so that it cannot be used for food. Condemned meat is sent to local rendering plants. Condemned animals are slaughtered and sent the same way. No provision is made for compensating the consignee in case shipments are con. demned. He is left to adjust that with the shipper.

\section{MILWAUKEE, WIS.}

\section{By John A. Butler, Milwaukee, Wis.}

The Chicago and Milwaukee stock yards furnish Milwaukee with its supply of meat, and the railway shipments are large. The present condition of local slaughter houses is good. The city is very fortunate in its present health commissioner, Dr. G. A. Bading, who is competent and energetic and thoroughly alive to the sanitary necessities of the population. He was not only the first municipal health commissioner to make a drastic and thorough inspection of the condition of the local meat supply after the Neills-Reynolds 